AUTHOR CORRECTION

\title{
Author Correction: The role of leptin and low testosterone in obesity
}

Kajal Khodamoradi, Zahra Khosravizadeh, Deepa Seetharam (D), Suresh Mallepalli, Natoli Farber and Himanshu Arora (D)

(c) The Author(s), under exclusive licence to Springer Nature Limited 2022

IJIR: Your Sexual Medicine Journal; https://doi.org/10.1038/s41443-022-00548-6

Correction to: International Journal of Impotence Research https:// doi.org/10.1038/s41443-022-00534-y, published online 31 January 2022

The citation for Figure 2 was missing. It reads as follows:
Grossmann M. Testosterone and glucose metabolism in men: current concepts and controversies. J Endocrinol. 2014;220: R37-55.

The original article has been revised. 